\title{
EFFECT OF DOLOMITE POWDER ON COMBUSTION AND TECHNOLOGICAL PROPERTIES OF WPC AND NEAT POLYPROPYLENE
}

\author{
FERHAT ÖZDEMIR ${ }^{1}$ NADIR AYRILMIS ${ }^{2 *}$ AND FATIH MENGELOĞLU \\ ${ }^{1}$ Department of Wood Chemistry, Forestry Faculty, Sutcu Imam University, 46100, Kahramanmaras, Turkey \\ ${ }^{2}$ Department of Wood Mechanics and Technology, Forestry Faculty, Istanbul University, 34473, Sariyer, Istanbul, Turkey \\ ${ }^{3}$ Department of Wood Mechanics and Technology, Forestry Faculty, Sutcu Imam University, 46100, Kahramanmaras, Turkey
}

\begin{abstract}
Water resistance, mechanical properties, and limiting oxygen index (LOI) of wood plastic composites (WPCs) and neat polypropylene filled with different amounts (3, 6, and $9 \%$ by weight) of dolomite powder and wood flour ( 15 and 30 by weight) were investigated. Wood flour, dolomite powder, polypropylene, and wax were dry-mixed in a high-intensity mixer to produce a homogeneous blend. This blend was then compounded in a laboratory-scale single screw extruder. Test specimens were produced by injection moulding process from the pellets dried to moisture content of $1 \%$. The thickness swelling and water absorption of the dolomite polypropylene composites (DPCs) and WPCs slightly increased with increasing dolomite powder content but the differences were not significant. The flexural modulus and tensile modulus of the WPCs and DPCs increased with increasing dolomite powder content while the flexural strength and tensile strength slightly decreased. The LOI of the WPCs and DPCs increased with increasing dolomite powder content, which extended the times to ignition of WPC and polypropylene. Based on the findings obtained from the present study, it can be said that $6 \mathrm{wt} \%$ dolomite powder is the optimum amount in the manufacture of WPC and DPC.
\end{abstract}

Keywords: Dolomite powder; mechanical properties; Combustion; wood plastic composite

Running head: Dolomite powder filled WPC and polypropylene

\section{INTRODUCTION}

Wood plastic composites (WPCs) are a group of new materials made from a combination of wood particles and thermoplastic resins. Recently, WPCs are increasingly being used in applications in the furniture, automotive, or building industry. However, thermoplastic users are continually seeking new ways to improve product performance. For thermoplastic composite industry, wood filler has many advantages such as low cost, low density, acceptable specific strength and good thermal insulation properties, renewable resource, and recycling possible without affecting the environment. However, its major drawbacks are susceptible to fungi attack, hygroscopicity, and flammability.

The suitability and end use applications of WPCs are highly related to mechanical properties such as tensile strength and modulus, bending strength and modulus, hardness, and physical properties such as dimensional stability and density of these products. A good understanding of the strength properties of WPCs is of considerable importance for especially semi-structural building products, such as decking, siding, and roofing. ${ }^{2}$ The ultimate optimization of WPC needs a thorough understanding of material performance and a wideranging evaluation of mechanical properties intended for desired applications.

Organic fillers such as wood and agricultural fibers have characteristics of low density, biodegradability, and sustainable productivity. Inorganic fillers such as calcium carbonate and talc have attracted a great attention because of their cost efficiency and abundance. The fillers (organic or inorganic materials) generally increase stiffness, strength, and hardness of polymer composites. Hetzer et al. ${ }^{4}$ reported that the addition of nanoclay in the presence of a maleic anhydride grafted polyethylene (MAPE) compatibilizer blend resulted in an increase of the modulus and strength of the composites. Gwon et al. ${ }^{3}$ used three types of inorganic fillers (talc, kaolin, and zincborate) for manufacturing WPCs. They reported that the kaolin filler showed the best performance in mechanical strength because of its staked plate shape, small particle size, and highly hydrophilic property of its surface. In other study, Zhou et al. ${ }^{5}$ reported that the tensile strength of polypropylene composites increased with increasing content of tetrapod-like zinc oxide whiskers in the range of $0-4 \mathrm{vol} \%$.

Dolomite is an inorganic filler and occurs widely in nature. It comprises of calcium magnesium carbonate found in crystalline form with a high degree of whiteness. ${ }^{6}$ Dolomite has being found to be a solid mineral of great importance, which has found its uses in various aspect of life. Although generally similar to calcite in properties, it is slightly harder (mohs hardness: 3.5$)$, denser $(2.85 \mathrm{~g}$ / $\mathrm{cm}^{3}$ ), and more acid resistant. ${ }^{7}$ Dolomite is rock forming mineral which is noted for its remarkable wettability and dispersibility as well as its moderate oil and plasticizers absorption. It has got increased weathering resistance capacity. ${ }^{8}$ In adhesives and sealants dolomite is an effective functional filler providing many benefits over calcites. Dolomite has not been widely known by WPC industry, although it has siginifcant advantages such as effective fire retardant, white color, low cost, easy-supply.

The goal of the present study was to investigate the effect of dolomite powder content on the water resistance, mechanical properties, and the relative flammability (limiting oxygen index (LOI)) of WPCs and dolomite polypropylene composites (DPCs). The percentage composition of dolomite powder used in the WPCs and and DPCs ranged from 3 to $9 \%$ by weight.

\section{EXPERIMENTAL}

\section{Materials}

Poplar sawdust was supplied by a commercial lumber manufacturer in Turkey. The wood flour was first air-dried, then ground with a high-speed rotary cutting using a Wiley mill, and finally screened. The wood flour passing through a $40-$ mesh $(0.42 \mathrm{~mm})$ screen and retained on a 60 mesh $(0.25 \mathrm{~mm})$ screen were used in the experiments. Before compounding, the wood flour was dried to 0 to $1 \%$ moisture content using a laboratory oven at $100{ }^{\circ} \mathrm{C}$ for $48 \mathrm{~h}$. The high white dolomite powder supplied by Doltaş Company in Izmir Turkey was used. The average particle size, density, and mohs hardness of the dolomite were $0.1 \mathrm{~mm}, 2.86 \mathrm{~g} \mathrm{~cm}^{-3}$ and $3.5-4$, respectively. Its crystal structure was hexagonal. The chemical composition of dolomite is presented in Table 1. The dolomite flour was dried overnight at $100{ }^{\circ} \mathrm{C}$ to remove residual moisture, which could cause microbubbles in compound granule in the extruder. In this study, we did not use the coupling agent to determine the pure effect of dolomite powder on the properties of WPC.

Table 1. Chemical composition of dolomite [9].

\begin{tabular}{ccc}
\hline Chemical composition & Unit & Value \\
\hline $\mathrm{CaO}$ & $\% \mathrm{wt}$ & 31.1 \\
$\mathrm{MgO}$ & $\% \mathrm{wt}$ & 21.04 \\
$\mathrm{Fe}_{2} \mathrm{O}_{3}$ & $\% \mathrm{wt}$ & 0.03 \\
$\mathrm{SiO}_{2}$ & $\% \mathrm{wt}$ & 0.22 \\
$\mathrm{Al}_{2} \mathrm{O}_{3}$ & $\% \mathrm{wt}$ & 0.02 \\
$\mathrm{Na}_{2} \mathrm{O}$ & $\% \mathrm{wt}$ & 0.01 \\
$\mathrm{~K}_{2} \mathrm{O}$ & $\% \mathrm{wt}$ & 0.01 \\
\hline
\end{tabular}


The polypropylene (Petoplen $\left.\mathrm{MH} 418^{\mathrm{TM}}\right)\left(\mathrm{T}=160{ }^{\circ} \mathrm{C}\right.$, density $=0.9 \mathrm{~g}$ $\left.\mathrm{cm}^{-3}, \mathrm{MFI} / 230^{\circ} \mathrm{C} / 2.16 \mathrm{~kg}=4-6 \mathrm{~g} 10^{-\mathrm{min}}\right)$ as polymer matrix was supplied by Petkim Inc. in Izmir city, Turkey. Paraffin wax (K.130. 1000Cas) (crystal form, softening point: $56-58^{\circ} \mathrm{C}$ ) was supplied by Izmir Technical Chemical company, Izmir city, Turkey.

\section{Manufacture of injection molded WPC and DPCs}

Polypropylene, wood flour, dolomite powder, and wax were dry-mixed in a high-intensity mixer to produce a homogeneous blend. The blend was then compounded in a laboratory scale single screw extruder at $40 \mathrm{rpm}$ screw speed in the temperatures (barrel to die) of $170-180-185-190-200^{\circ} \mathrm{C}$, respectively. The extruded specimens were collected, cooled, and granulated into the pellets. The pellets were stored in a sealed container and then dried to $0-1 \%$ moisture content in an oven for 24-h before being injection molded. The dried pellets was then injection molded using an HDX-88 injection molding machine (pressure: 150 bar; injection speed: $80 \mathrm{~mm} \mathrm{sec}^{1}$; screw speed: $40 \mathrm{rpm}$ ) to produce standard test specimens. Finally, the specimens were conditioned at a temperature of $23 \pm 2{ }^{\circ} \mathrm{C}$ and relative humidity of $50 \pm 5 \%$ according to ASTM D 618. The raw material formulations of WPCs and DPCs are presented in Table 2. The density of WPCs varied from 0.91 to $1.04 \mathrm{~g} \mathrm{~cm}^{-3}$.

Table 2. Experimental design.

\begin{tabular}{ccccc}
\hline \multirow{2}{*}{$\begin{array}{c}\text { Composite } \\
\text { type }\end{array}$} & $\begin{array}{c}\text { Wood } \\
\text { flour } \\
\text { (wt \%) }\end{array}$ & $\begin{array}{c}\text { Polypropylene } \\
\text { (wt \%) }\end{array}$ & $\begin{array}{c}\text { Composite compositon } \\
\text { powder } \\
\text { (wt \%) }\end{array}$ & $\begin{array}{c}\text { Wax content } \\
\text { (wt \%) }\end{array}$ \\
\hline A & 15 & 79.5 & 3 & 2.5 \\
B & 15 & 76.5 & 6 & 2.5 \\
C & 15 & 73.5 & 9 & 2.5 \\
D & 30 & 64.5 & 3 & 2.5 \\
E & 30 & 61.5 & 6 & 2.5 \\
F & 30 & 58.5 & 9 & 2.5 \\
G & 0 & 100 & 0 & 2.5 \\
H & 0 & 94.5 & 3 & 2.5 \\
I & 0 & 91.5 & 6 & 2.5 \\
J & 0 & 88.5 & 9 & 2.5 \\
\hline
\end{tabular}

\section{Determination of dimensional stability}

The thickness swelling (TS) and water absorption (WA) tests were carried out according to ASTM D 570. The TS and WA tests were performed on the same specimen. The test specimens were in the form of a disk $50.8 \mathrm{~mm}$ in diameter and $3.2 \mathrm{~mm}$ in thickness. The conditioned specimens were entirely immersed for 1-day, 8-days, and 28-days in a container of water at $23{ }^{\circ} \mathrm{C}$. At the end of each immersion time, the specimens were taken out from water and all surface water was removed with a clean dry cloth. The specimens for the WA test were weighed to the nearest $0.01 \mathrm{~g}$. After the weight measurements, the thickness of the same specimens for the TS test was measured to the nearest $0.001 \mathrm{~mm}$ immediately. Seven replicate specimens were tested for each type of composite. The density of the specimens was determined according to ASTM D 792 .

Determination of mechanical properties

Flexural modulus and strength of the specimens with dimensions of 127 $\mathrm{mm} \times 12.7 \mathrm{~mm} \times 3.2 \mathrm{~mm}$ (thickness) were measured in three-point bending test using a universal testing machine (Zwick Roell Z010, capacity $10 \mathrm{kN}$ ) at a crosshead speed of $1.3 \mathrm{~mm} \mathrm{~min}^{-1}$ in accordance with ASTM D 790. Tensile strength and modulus of the specimens [dogbone shape (type III)] were tested with a crosshead speed of $5 \mathrm{~mm} \mathrm{~min}^{-1}$ in accordance with ASTM D 638. Seven replicate specimens were tested for the tensile and flexural properties of each composite formulation.

\section{Limiting oxygen index (LOI) test}

The LOI is the minimum percentage oxygen that is required to maintain flaming combustion of a specimen under specified laboratory conditions. The LOI measurements were carried out using a Dynisco Limiting Oxygen Index Chamber according to the principles of ASTM D2863. The specimens with dimensions of $4 \mathrm{~mm}$ by $100 \mathrm{~mm}$ were placed vertically in the center of the glass column using a specimen holder and then burned in a precisely controlled atmosphere of nitrogen and oxygen. Three specimens were used for each type of WPC and DPC.

Statistical analysis

An analysis of variance, ANOVA, was conducted $(\mathrm{p}<0.05)$ to evaluate the effect of the dolomite content on the water resistance, mechanical properties, and LOI of the WPC and DPC. Significant differences among the average values of the WPC and DPC types were determined using Duncan's multiple range tests. The statistical comparison for each test was done among all the composite types (from A to J).

\section{RESULTS AND DISCUSSION}

\section{Water resistance of WPCs and DPCs}

Table 3 shows the TS and WA values of the WPCs and neat polypropylene filled with increasing content of the dolomit powder. Significant differences $(\mathrm{p}<0.05)$ are shown by letters in Table 3 . The TS and WA values of the WPCs and DPCs increased with the increase of dolomite powder. However, the increments in the TS and WA values were not significant at the same content of the wood flour (Table 3). Among the WPCs, the lowest TS and WA values were obtained from the WPCs without the dolomite powder while the highest TS and WA values were obtained from the WPCs containing $9 \mathrm{wt} \%$ dolomite powder. The one-day WA values of WPCs at the $15 \mathrm{wt} \%$ wood flour content increased from 0.08 to $0.14 \%$ as the amount of the dolomite powder increased from 3 to $9 \mathrm{wt} \%$.(Table 3 ). A similar result was observed for the WA property. This was mainly attributed to the decrement in the polypropylene content and the chemical structure of the dolomit powder. The TS values were found to be higher than the WA values. The TS and WA values of the specimens significantly increased as the immersion time increased from 1 day to 28 days.

The TS and WA of DPCs were slightly increased by the incorporation of the dolomite powder. For example, as the $9 \mathrm{wt} \%$ dolomite powder was incorporated into the neat polypropylene, 28 days TS and WA values of the specimens (type J) were found to be $0.29 \%$ and $0.21 \%$, respectively. These properties were found to be $0.24 \%$ and $0.18 \%$ for the neat PP composite (type $\mathrm{G})$, respecetively. As for the neat PP composite, similar results were found in previous studies. ${ }^{10,11}$ For example, Ayrilmis et al. ${ }^{10}$ reported that 28 days TS and WA values of the neat PP composite were $0.24 \%$ and $0.18 \%$. From the results, the neat PP composite showed the lowest WA value, followed by the composites with dolomite filler and wood filler, respectively. The WPCs having higher amounts of wood and dolomite exhibit higher WA due to increase number of micro voids on the surface which was caused by the higher amount of poor bonded area between the filler and polymer matrix (Fig 1c). The WA and TS of the DPCs filled with the dolomite powder were significantly lower than those of the WPCs. This was attributed to the hydrophilic property of wood because of its functional polar groups such as hydroxyl groups. The WA of WPCs mainly depends on their porosity, presence of interfacial voids between the wood filler and polymer matrix, and the amount of wood filler. The WA values of the WPC specimens containing the dolomit powder significantly increased as the amount of the wood flour increased from 15 to $30 \mathrm{wt} \%$. This was mainly due to the hygroscopic property of wood and interfacial voids between the wood filler and polymer matrix, as shown in Figure 1. Previous studies reported that the TS and WA of WPCs were significantly increased by increasing wood flour content due to the hydrophilic property of wood. ${ }^{12-14,15}$

The WA and TS of the thermoplastic composites filled with the natural fibers are important properties which have deleterious effects on the mechanical and physical properties of the composites. Polypropylene is a hydrophobic polymer with extremely low moisture sorption and diffusion capability. However, the wood is a hygroscopic material due to its hydrophilic polymers, (cellulose and hemicelluloses) bearing many accessible hydroxyl groups. The water molecules easily bond to the hydroxyl groups via hydrogen bonding and push apart the fibrils causing the cell wall to swell. ${ }^{16}$ Hydroxyl groups are responsible for dimensional changes of thermoplastic composites filled with the natural fibers. Water absorption mainly depends on the amount of micro voids and cracks in the composites. Any increase in the cracks and voids led to increase in the water absorption. The penetration of water molecules into the fiber cell walls results in thickness swelling of the natural fiber filled thermoplastic composites due to affected hydrophilic cellulose and hemicelluloses.

Mechanical properties of WPCs and DPCs

The mechanical properties of the WPCs and polypropylene were summarized in Table 4. Significant differences $(p<0.05)$ are shown by letters in Table 4. The tensile modulus of the WPCs and DPCs increased with increasing content of the dolomite powder but the increment was not significant (Table 4). 
At the $15 \mathrm{wt} \%$ wood flour content, the flexural modulus increased from 1592 to $1673 \mathrm{MPa}$ as the amount of dolomite powder increased from 3 to $9 \mathrm{wt} \%$. However, at the $30 \mathrm{wt} \%$ wood flour content, the flexural modulus of the WPCs did not improved with increasing dolomite powder content.

Table 3. Density, thickness swelling, and water absorption of WPCs and DPCs depending on the amount of dolomite powder.

\begin{tabular}{|c|c|c|c|c|c|c|c|}
\hline \multirow{2}{*}{$\begin{array}{c}\text { Composite } \\
\text { type }\end{array}$} & \multirow{2}{*}{$\frac{\text { Density }}{\left(\mathrm{g} \mathrm{cm}^{-3}\right)}$} & \multicolumn{3}{|c|}{ Thickness swelling (TS) (\%) } & \multicolumn{3}{|c|}{ Water absorption (WA) (\%) } \\
\hline & & 1 day & 8 days & 28 days & 1 day & 8 days & 28 days \\
\hline A & $0.94(0.01)$ & $0.57(0.05) b$ & $0.99(0.05) \mathrm{b}$ & $1.32(0.05) b$ & $0.08(0.02) \mathrm{a}$ & $0.20(0.02) \mathrm{a}$ & $0.38(0.01) b$ \\
\hline $\mathrm{B}$ & $0.96(0.01)$ & $0.63(0.02) b$ & $1.20(0.03) b c$ & $1.64(0.03) b c$ & $0.10(0.03) \mathrm{a}$ & $0.27(0.02) \mathrm{a}$ & $0.41(0.18) b$ \\
\hline $\mathrm{C}$ & $0.97(0.02)$ & $0.72(0.01) a b$ & $0.96(0.01) \mathrm{b}$ & $1.74(0.01) b c$ & $0.14(0.03) \mathrm{a}$ & $0.31(0.03) \mathrm{a}$ & $0.50(0.06) b$ \\
\hline $\mathrm{D}$ & $1.00(0.03)$ & $0.77(0.02) a b$ & $1.40(0.01) \mathrm{cd}$ & $1.88(0.02) \mathrm{c}$ & $0.31(0.08) b$ & $0.56(0.08) b$ & $1.08(0.17) \mathrm{c}$ \\
\hline $\mathrm{E}$ & $1.03(0.01)$ & $0.82(0.01) \mathrm{ab}$ & $1.44(0.02) \mathrm{cd}$ & $1.97(0.02) \mathrm{c}$ & $0.34(0.08) b$ & $0.65(0.09) \mathrm{b}$ & $1.28(0.12) \mathrm{d}$ \\
\hline $\mathrm{F}$ & $1.04(0.01)$ & $0.92(0.03) b$ & $1.60(0.03) \mathrm{d}$ & $2.13(0.03) \mathrm{c}$ & $0.40(0.06) b$ & $0.71(0.07) b$ & $1.30(0.16) \mathrm{d}$ \\
\hline G & $0.91(0.01)$ & $0.12(0.01) \mathrm{a}$ & $0.14(0.01) \mathrm{a}$ & $0.24(0.01) \mathrm{a}$ & $0.06(0.02) \mathrm{a}$ & $0.10(0.01) \mathrm{a}$ & $0.18(0.02) \mathrm{a}$ \\
\hline $\mathrm{H}$ & $0.92(0.02)$ & $0.13(0.01) \mathrm{a}$ & $0.15(0.01) \mathrm{a}$ & $0.26(0.01) \mathrm{a}$ & $0.07(0.02) \mathrm{a}$ & $0.11(0.01) \mathrm{a}$ & $0.19(0.01) \mathrm{a}$ \\
\hline I & $0.93(0.01)$ & $0.14(0.01) \mathrm{a}$ & $0.16(0.01) \mathrm{a}$ & $0.27(0.01) \mathrm{a}$ & $0.07(0.01) \mathrm{a}$ & $0.12(0.01) \mathrm{a}$ & $0.19(0.01) \mathrm{a}$ \\
\hline $\mathrm{J}$ & $0.96(0.02)$ & $0.16(0.01) \mathrm{a}$ & $0.19(0.01) \mathrm{a}$ & $0.29(0.01) \mathrm{a}$ & $0.08(0.02) \mathrm{a}$ & $0.14(0.01) \mathrm{a}$ & $0.21(0.02) \mathrm{a}$ \\
\hline
\end{tabular}

${ }^{1}$ See Table 1 for composite formulation.

${ }^{2}$ Composite types (from A to J) with same letters in column indicate that there is no statistical difference $(\mathrm{p}<0.05)$ between the specimens according to Duncan's multiply range test. The values in the parentheses are standard deviations.

Table 4. Mechanical properties of WPCs and DPCs depending on the amount of dolomite powder.

\begin{tabular}{cccccc}
\hline Composite type & $\begin{array}{c}\text { Tensile } \\
\text { strength } \\
(\mathrm{MPa})\end{array}$ & $\begin{array}{c}\text { Tensile } \\
\text { modulus } \\
(\mathrm{MPa})\end{array}$ & $\begin{array}{c}\text { Elongation } \\
\text { at break } \\
(\%)\end{array}$ & $\begin{array}{c}\text { Flexural strength } \\
(\mathrm{MPa})\end{array}$ & $\begin{array}{c}\text { Flexural modulus } \\
(\mathrm{MPa})\end{array}$ \\
\hline $\mathrm{A}$ & $24.8(0.16) \mathrm{c}$ & $615(28) \mathrm{b}$ & $20.1(1.75) \mathrm{a}$ & $42.4(0.86) \mathrm{ef}$ & $1592(27) \mathrm{c}$ \\
$\mathrm{B}$ & $24.4(0.38) \mathrm{bc}$ & $620(53) \mathrm{b}$ & $22.2(0.93) \mathrm{a}$ & $41.0(1.26) \mathrm{de}$ & $1617(58) \mathrm{cd}$ \\
$\mathrm{C}$ & $22.8(1.32) \mathrm{a}$ & $627(37) \mathrm{b}$ & $19.4(1.49) \mathrm{a}$ & $41.8(0.40) \mathrm{ef}$ & $1673(15) \mathrm{d}$ \\
$\mathrm{D}$ & $23.3(0.71) \mathrm{ab}$ & $722(26) \mathrm{c}$ & $20.3(0.92) \mathrm{a}$ & $42.8(0.88) \mathrm{f}$ & $2051(64) \mathrm{f}$ \\
$\mathrm{E}$ & $22.7(0.95) \mathrm{a}$ & $730(59) \mathrm{c}$ & $20.2(1.29) \mathrm{a}$ & $41.7(0.56) \mathrm{ef}$ & $1962(40) \mathrm{e}$ \\
$\mathrm{F}$ & $22.7(0.95) \mathrm{a}$ & $739(42) \mathrm{c}$ & $19.9(0.34) \mathrm{a}$ & $41.9(1.12) \mathrm{ef}$ & $2044(50) \mathrm{f}$ \\
$\mathrm{G}$ & $27.1(2.44) \mathrm{d}$ & $474(34) \mathrm{a}$ & $29.4(6.71) \mathrm{b}$ & $37.1(0.71) \mathrm{a}$ & $1013(19) \mathrm{b}$ \\
$\mathrm{H}$ & $29.0(0.59) \mathrm{e}$ & $503(73) \mathrm{a}$ & $19.8(1.15) \mathrm{a}$ & $39.0(1.22) \mathrm{bc}$ & $1060(11) \mathrm{b}$ \\
$\mathrm{I}$ & $29.2(0.17) \mathrm{e}$ & $531(70) \mathrm{a}$ & $14.3(0.40) \mathrm{a}$ & $39.4(1.80) \mathrm{ab}$ & $1083(84) \mathrm{a}$ \\
$\mathrm{J}$ & $28.6(0.47) \mathrm{e}$ & $543(81) \mathrm{a}$ & $14.1(0.76) \mathrm{a}$ & $39.9(0.84) \mathrm{cd}$ & $1110(42) \mathrm{b}$ \\
\hline
\end{tabular}

${ }^{1}$ See Table 2 for composite formulation.

${ }^{2}$ Composite types (from A to J) with same letters in column indicate that there is no statistical difference $(\mathrm{p}<0.05)$ between the specimens according to Duncan's multiply range test. The values in the parentheses are standard deviations.

The tensile strength and flexural strength of the WPCs were slightly decreased by the incorporation of the dolomite powder. However, the flexural strength of the DPCs increased from 39.0 to $39.9 \mathrm{MPa}$ as $9 \mathrm{wt} \%$ dolomite was added into the composite, but this was not significant (Table 4). The tensile strength of the DPCs decreased as the amount of the dolomite powder was beyond $6 \mathrm{wt} \%$, but it was higher than that of the neat polypropylene (Table 4). A similar result was found in a previous study. ${ }^{17}$ It was reported that the tensile strength of PVC composites decreased after $7.5 \mathrm{wt} \%$ dolomite powder was incorporated into the PVC. The reduction in the tensile strength of the WPCs beyond $6 \mathrm{wt} \%$ dolomite powder was mainly attributed to the poor compatibility between the dolomite powder and polypropylene, which formed the weak interfacial regions, as shown in Figure 1c.

The results of tensile and flexural modulus tests showed that the dolomite powder and wood flour allow efficient stress transfer from the polymer matrix to the reinforcing filler. Introducing organic and inorganic fillers modify the mechanical behavior by making the material stiffer, which is characterized by the significantly decreased failure strain. ${ }^{18}$ This behavior was described in similar studies and explained by the reduction of polymer chains mobility in the presence of the filler. ${ }^{18-21}$ In addition, the improvement in the tensile modulus of the WPCs and DPCs containing the dolomite powder can be explained by the fact that the hardness of inorganic fillers is harder than that of the polypropylene and contribute to the hardness of the composite, which results in higher values of modulus. ${ }^{22}$ The tensile elongation at break of the WPCs decreased with increasing dolomit powder content but the decrement was not significant. For example, the elongation at break of the WPCs at $15 \mathrm{wt} \%$ wood flour content decreased from 20.1 to $19.4 \%$ as the amount of dolomite powder increased from 3 to $9 \mathrm{wt} \%$. At the $30 \mathrm{wt} \%$ wood flour content, the elongation at break values of the WPCs (20.3 to $19.9 \%$ ) were not significantly affected by the increased dolomite powder content

As the wood flour or dolomite powder was incorporated into the polypropylene, incompatible interfacial regions between the filler and polypropylene were created. The SEM micro images of the dolomite powder and the fracture surface of tensile specimen (WPC type F) are presented in Figure 1. As shown in Figure 1b, the dolomite particules were encapsulated by 
the polypropylene matrix. It was observed the micro voids and weakened the interfacial bonding regions between wood flour and polymer matrix in Figure $1 \mathrm{c}$. This was mainly attributed to the incompability between the wood flour and polymer matrix.

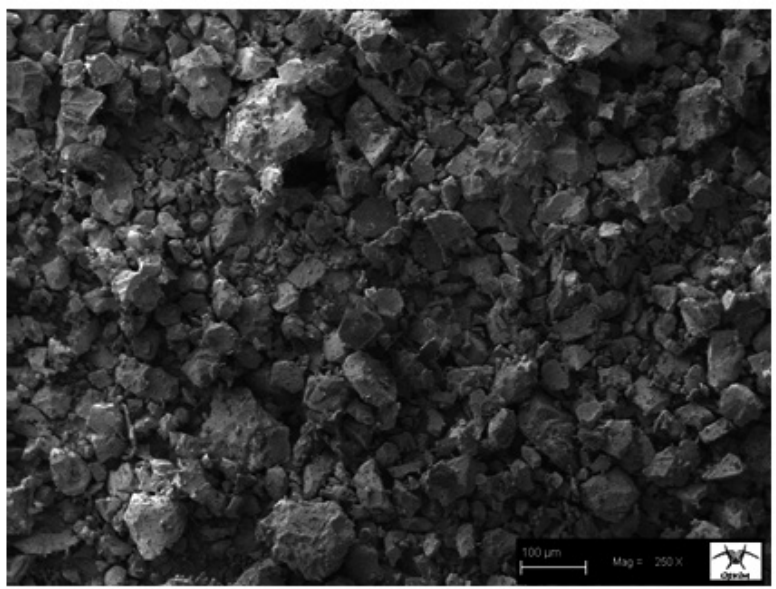

A. Dolomite (x250)

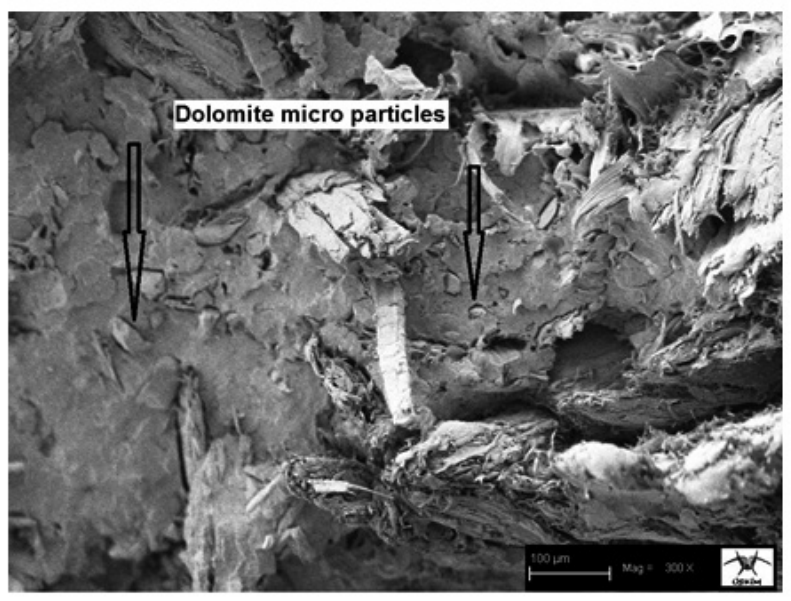

B. WPC $(x 300)$

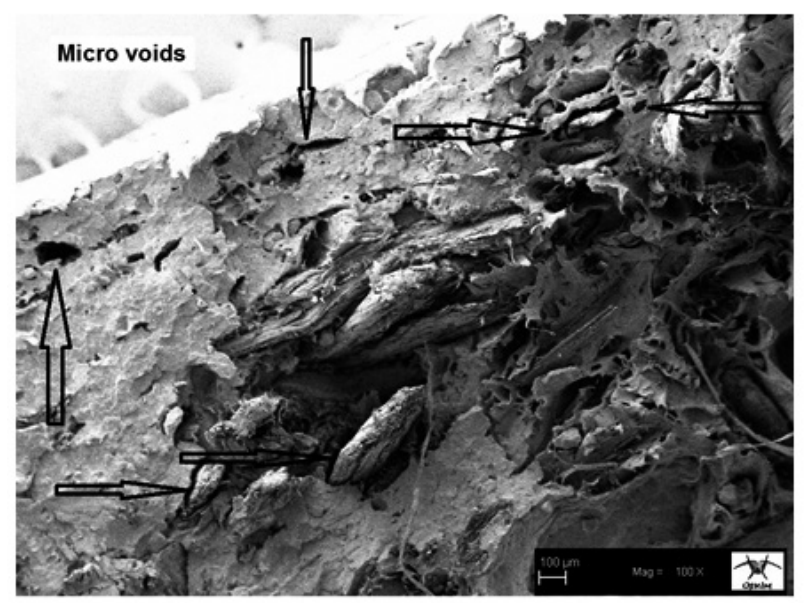

C. Micro voids in the WPC (x100).

Figure 1. SEM micro images. A. dolomite powder. B. dolomite powder in the WPC. C. Micro voids in the WPC (Fracture surface of tensile WPC specimen containing dolomite).
LOI property of WPCs and DPCs

The LOI test assumes that inherently less flammable materials required greater oxygen concentrations to produce the heat necessary for the continued production of flammable volatiles and flame propagation. ${ }^{23}$ The changes in the LOI of polypropylene and WPC depending on the amount of dolomite powder were presented in Figure 2.

The addition of dolomite powder into the WPC and polypropylene improved the maximum flame retardancy as evident from higher LOI value. However, the improvement in the LOI was not significant. As the content of the dolomite powder increased from 3 to $9 \%$, there was a relative rise in the LOI of the WPCs. For example at $15 \mathrm{wt} \%$ wood flour content, the LOI values of the WPCs increased from 19.6 to $20.8 \%$ as the amount of dolomite powder increased from 3 to $9 \mathrm{wt} \%$. The LOI results were consistent with previous studies showing the positive effect of inorganic fillers on the flame resistance of thermoplastic composites..$^{24,25}$

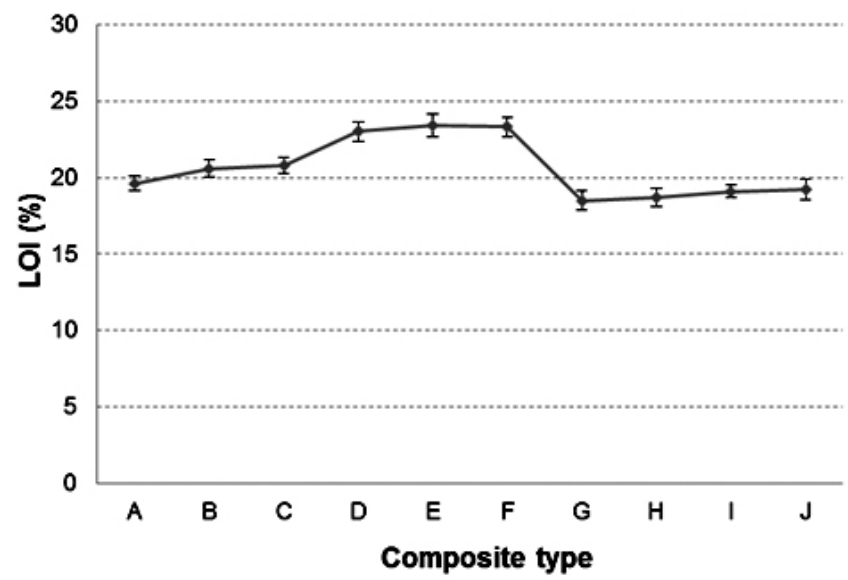

Figure 2. The LOI of WPCs and DPCs depending on the amount of dolomite powder.

Dolomite contains a magnesium-rich mineral. Fire retardants containing magnesium such as magnesium hydroxide have the characteristics of flame retarding, smoke suppression, and promoting charring. ${ }^{26-29} \mathrm{Wu}$ et al. ${ }^{28}$ reported that LOI of WPCs decreased with increasing magnesium hydroxide content. Magnesium hydroxide can improve the char structure which plays an important role in reducing the degradation speed of the inner matrix during combustion process and increases the char residue at high temperature. ${ }^{28}$ Magnesium hydroxide withdraws heat from the plastic during its decomposition into magnesium oxide and water. Water vapor that is generated dilutes the fuel supply to the flame. Decomposition products insulate the plastic from heat and produce char that impedes the flow of potentially flammable gases to the flame. ${ }^{30}$

The LOI value of the WPC, namely oxygen concentration, was considerably increased by the addition of wood flour content (Fig. 2). For example, as the amount of wood flour increased from 15 to $30 \mathrm{wt} \%$ in the WPC containing $3 \mathrm{wt} \%$ dolomite powder, the LOI value increased from 19.6 to $23 \%$. Similar results were observed for $6 \mathrm{wt} \%$ and $9 \mathrm{wt} \%$ loading levels of the dolomite powder. It has been reported that fire resistance of polypropylene can be considerably improved by enhancement of amount of wood flour. ${ }^{14}$ Wood has some initial or natural fire resistance because of its low thermal conductivity and ability to char formation. ${ }^{31}$

The LOI value of the neat polypropylene was found to be $18.5 \%$. As 9 $\mathrm{wt} \%$ dolomite powder was incorporated into the neat polypropylene, the LOI increased from 18.5 to $19.2 \mathrm{wt} \%$. Our results were consistent with LOI results for untreated wood and plastics reported in the literature. The LOI values of 22.0 to $25.1 \%$ were reported in the literature for $3 \mathrm{~mm}$ by $6.5 \mathrm{~mm}$ by 100 $\mathrm{mm}$ specimens of sawn southern pine. ${ }^{32}$ The LOI value of neat polypropylene was reported as $17.5 \%$ in the literature. ${ }^{33}$ Since the LOI test is widely used in evaluating the flammability of plastics, it was used in this study as an initial evaluation of the flammability of the DPCs and WPC containing dolomite powder. However, it should be noted that the LOI test has limited value in predicting corresponding results in other types of fire tests and real fires. 


\section{CONCLUSIONS}

The results of this study showed that the tensile modulus and flexural modulus of the WPCs and DPCs increased with the incorporation of the dolomite powder while the tensile strength and flexural strength decreased. As for the DPCs, the flexural strength and tensile strength were improved by the incorporation of dolomite powder. The dolomite powder slightly increased the TS and WA of the WPCs and neat polypropylene The LOI value of the WPC was increased by the addition of the wood flour content. However, the improvemen in the LOI was not significant. Based on the findings obtained from the present study, it can be said that $6 \mathrm{wt} \%$ dolomite powder is the optimum amount in the manufacture of WPC. The bending and tensile properties of the polypropylene composites improved with increasing dolomite powder upto $9 \mathrm{wt} \%$.

\section{REFERENCES}

1. A.K. Bledzki, J. Gassan, Prog. Polym. Sci. 24, 221, (1999)

2. A. Kaymakci, N. Ayrilmis, Compos. Part B 58, 582, (2014).

3. F. Orellana, J. Lisperguer, C. Nunez, J. Chil. Chem. Soc. 59, 2389, (2014).

4. J.G. Gwon, S.Y. Lee, S.J. Chun, G.H. Doh, J.H. Kim, J. Compos. Mater 46, 301, (2012).

5. M. Hetzer, J. Naiki, H. Zhou, T. Poloso, D.D. Kee, J. Compos. Mater. 43, 2285, (2009).

6. J.P. Zhou, K.Q. Qiu, W.L. Fu, J. Compos. Mater. 39, 1931, (2005).

7. A.O. Adesakin, O.O. Ajayi, P.E. Imosili, B.E. Attahdaniel, S.O.O. Olusunle, Chem. Mater. Res. 3, 36, (2013).

8. J. Jancar, E. Fekete, P.R. Hornsby, Mineral fillers in thermoplastics I: raw materials and processing. Springer Science \& Business Media, Berlin, Germany, (1999).

9. S.N. Bhavsar, H.B. Joshi,, P.K. Shrof, P.J. Ankit, Int. J. Develop Res. 3, 158, (2014).

10. Dolomite Analysis Report. Doltas Mineral and Chemical Ltd. Com. Izmir, Turkey, (2009) (Accessed on 23 November 2009). Retrieved from http:// www.doltas.com/mtadolomitanalizraporu.pdf.

11. N. Ayrilmis, A. Kaymakci, F. Ozdemir, J. Appl. Polym. Sci. 129, 1170, (2013).

12. T. Morii, S. Tomioka, H. Hamada, Sci. Eng. Compos. Mater. 18, 87, (2011).

13. N. Ayrilmis, S. Jarusombuti, J. Compos. Mater. 45, 103, (2011).

14. A. Ayrilmis, J.T. Benthien, H. Thoemen, R.H. White, J. Appl. Polym. Sci. 122, 3201, (2011).

15. N. Ayrilmis, J.T. Benthien, H. Thoemen, R.H. White, Eur. J. Wood Prod. 70, 215, (2012).

16. C.H. Kurt, Determination of calcination characteristics of dolomite. MSc Thesis. Institute of Natural and Applied Sciences University of Cukurova, Adana, Turkey, (2010).

17. B. Mohebby, H. Younesi, A. Ghotbifar, S. Kazeimi-Najafi, J. Reinf. Plas. Compos. 29, 830, (2010).

18. B. Ghada, Z. Rachida, M. Ahmed, D. Faycal, Asian J. Chem. 22, 6687 , (2010)

19. D. Ndiaye, B. Diop, C. Thiandoume, P.A. Fall, A.K. Farota, A. Tidjani, Morphology and thermo mechanical properties of wood/polypropylene composites. Chapter 22, In F. Dogan (ed.), Polypropylene, InTech Publisher, Rijeka, Crotia, (2012).

20. M. Chaharmahali, M. Tajvidi, S.K. Najafi, Polym. Compos. 29, 606, (2008).

21. D.F. Caulfield, C. Clemons, R.E. Jacobson, R.M. Rowell, Wood thermoplastic composites, In Rowell, R. M. (Ed.), Handbook of wood chemistry and wood composites. CRC Press, Boca Raton USA, (2005).

22. T. Taj, Preparation and characterization of agro-wastes based polymer composites for commercial use. Ph.D. Thesis, University of Punjab, Lahore, Pakistan, (2009).

23. O. Martikka, Impact of mineral fillers on the properties of extruded woodpolypropylene composites. Ph.D. Thesis, Lappeenranta University of Technology, Lappeenranta, Finland, (2013).

24. X.Y Pang, M.K. Song, Y. Tian, M.W. Duan, J. Chil. Chem. Soc. 57, 1318, (2012).

25. B.K. Deka, T.K. Maji, Polym. Bullet. 67, 1875, (2011).

26. B.K. Deka, T.K. Maji, Polym. Eng. Sci. 52, 1516, (2012).

27. A. El-sabbagh, L. Steuernagel, G. Ziegmann, J. Reinf. Plast. Compos. 22, 1030, (2013)

28. M.N.S. Kumar, Siddaramaiah, T.M. Kotresh, I. Shekar, J.H. Jagannath, J. Reinf. Plast. Compos. 28, 537, (2009).

29. Z. Wu, N. Hu, Y. Wu, Z. Qin, J. Nanomater. Article ID 945308, 8 p, (2014).
30. A.B. Morgan, J.M. Cogen, R.S. Opperman, J.D. Harris, Fire Mater. 31, $387,(2007)$.

31. Stark NM, White RH, Mueller SA, T.A. Osswall, Polym. Degrad. Stabil. 95, 1903, (2010)

32. M.K. Kuzman, P. Grošelj, Wood Res. 57, 591, (2012).

33. R.H. White, Wood Sci. 12, 113, (1979).

34. S.H. Chiu, W.K. Wang, Polym. 39, 1951, (1998). 